\title{
Interrelations of Microstructure, Mechanical Properties and Fracture Behaviour in a Cr-Mo Steel ${ }^{*}$
}

\author{
By F.H. SAMUEL**
}

\begin{abstract}
Synopsis
Investigations have been carried out to determine the effect of structure viz., martensite, bainites and ferrite-carbide aggregates on the tensile and tear properties as well as the nature of fracture in a $0.11 \% \mathrm{C}-1.5 \% \mathrm{Mn}-$ $1.04 \% \mathrm{Cr}-0.25 \% \mathrm{Mo}-0.003 \% \mathrm{~B}$ steel. Both total elongation and uniform elongation vary almost linearly with tensile strength, the ratios of uniform elongation to total elongation being confined to 0.6 0.7. Replacing total elongation by uniform elongation to characterize the high strength-ductility combination is not found to be identical. The toughness (as measured by unit propagation energy) follows a trend almost similar to that of $T S \times E l$. Shear and/or microvoid coalescence are the operating modes of fracture and these, in turn, depend on the steel toughness and structure.
\end{abstract}

\section{Introduction}

During the last two decades, the market for highstrength tough steels having yield strength in the range $350 \sim 770 \mathrm{MNm}^{-2}$ has expanded rapidly. In low-carbon manganese steels a minimum $560 \mathrm{MNm}^{-2}$ yield strength is achieved with a ferrite-pearlite structure. Above this level the steel should contain bainite and/ or temper martensite structure. ${ }^{1)}$ Molybdenum and boron are very effective in improving the steel hardenability and, hence, enhance the bainite formation even on normalizing. 2,3) Chromium, like molybdenum, tends significantly to facilitate the bainite hardenability and promotes the occurrence of austenite bay. ${ }^{4)}$ In the present study an alloy is selected to contain $0.11 \% \mathrm{C}-1.5 \% \mathrm{Mn}-0.003 \% \mathrm{~B}$ to which $1 \% \mathrm{Cr}$ and $0.25 \%$ Mo were added. The findings of Gerberich et al. ${ }^{5)}$ show that in such steels a mixed bainitic-martensitic structure would exhibit better toughness than temper martensite structure. The existence of proeutectoid ferrite is not desirable due to its poor hardenability.

The effect of structure on the steel strength and toughness when it contains $0.15 \% \mathrm{C}$ and $1.5 \% \mathrm{Cr}$ and Mo has been studied by Kamada et al. ${ }^{6}$ ) and Kunitake et al. ${ }^{7)}$ Another school of thought ${ }^{8}$ suggested using a single parameter, the product of tensile strength and ductility to characterize the combination of strength and ductility as a function of microstructure.

The present investigation determines the effect of martensite, bainites and ferrite-carbide aggregates on the tensile properties, ductilities and toughness in the above mentioned steel and aims to correlate the variation in these parameters with fracture modes.

\section{Experimental Procedure}

An air-melted $\mathrm{Cr}-\mathrm{Mo}$ steel $(0.11 \% \mathrm{G}-1.5 \% \mathrm{Mn}-$
$1.04 \% \mathrm{Cr}-0.25 \% \mathrm{Mo}-0.003 \% \mathrm{~B})$ was received in the form of ingot $80 \times 80 \times 200 \mathrm{~mm}$ and hot forged into plates $6 \mathrm{~mm}$ thick. Specimens for heat treatment were cut from these plates and austenitized at 1000 ${ }^{\circ} \mathrm{C}$ for $1 \mathrm{hr}$ prior to either quenching in iced brine, cooling in air (normalizing) or transforming isothermally in molten baths. The quenched as well as normalized steels were subjected to isochronal tempering upto $700^{\circ} \mathrm{C}$.

Tensile tests were performed on shouldered specimens (Hounsfield No. 12 with gauge length $13 \mathrm{~mm}$ and diameter $4.5 \mathrm{~mm}$ ), whereas tear tests were carried out on specimens with dimensions shown in Fig. 1.9) All tests were conducted at room temperature using the same strain rate. The strain hardening exponent ' $n$ ' was calculated from the relation:

$$
\sigma=E \epsilon^{n}
$$

where, $\sigma, \epsilon:$ the true stress and strain, respectively $K, n$ : constants.

A scanning electron microscope was used in examining the microstructure of specimens, after polishing and etching in $2 \%$ nital, at $25 \mathrm{kV}$. Fractured surfaces of tear test specimens were investigated using the same microscope.

\section{Results and Discussion}

\section{Microstructure}

Photograph 1(a), shows the microstructure of quenched steel comprising packet martensite as would be expected for this grade of steel. Such packets are generally composed of several laths containing high dislocation densities. ${ }^{10}$ Although the martensite packets are retained on tempering at elevated temperatures, i.e., 600 and $700{ }^{\circ} \mathrm{C}$, Photo. $1(\mathrm{~b})$, the lath morphology is broken down into ferrite and carbide. ${ }^{11)}$ This process is associated with great dislocation annihilation and the formation of recovered and/or recrystallized ferrite grains. ${ }^{12}$ ) The microstructure obtained for normalized steel exhibit typical granular bainite, Photo. 2(a). In this case, as well, the granular bainite structure persists on tempering even at $700{ }^{\circ} \mathrm{C}$, Photo. 2(b), a temperature which represents recrystallization of bainite laths. ${ }^{\text {9) }}$

An isothermal transformation at $350{ }^{\circ} \mathrm{C}$ (a temperature below the $M_{s}$ ) results in mixed packets of martensite and lower bainite microstructure as shown in Photo. 3(a). Increasing the transformation temperature changes the structure to lower bainite at

* Received August 16, 1982. (C) 1983 ISIJ

** Central Metallurgical Research \& Development Institute, National Research Centre, Cairo, Dokki, Egypt. 
Fig. 1.

Schematic diagram for tear test specimen and load-expansion curve.

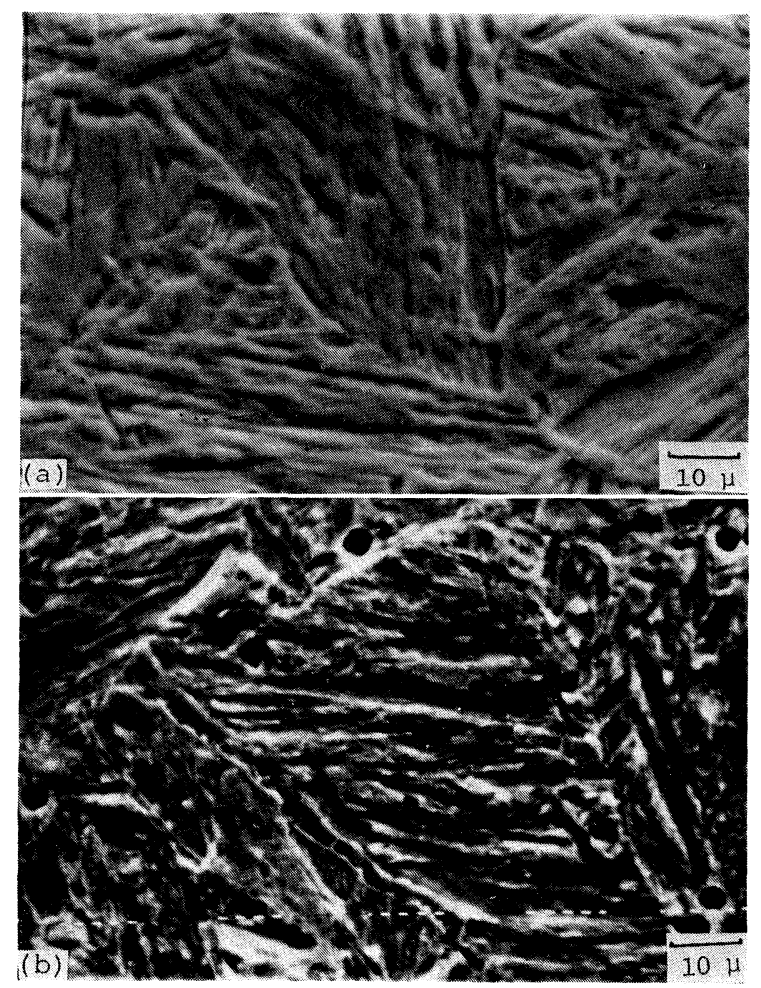

Photo. 1. Microstructure showing packet martensite in a) asquenched, and b) quenched and tempered at $600^{\circ} \mathrm{C}$.

$400{ }^{\circ} \mathrm{C}$, upper bainite at $450^{\circ} \mathrm{C}$ and granular bainite at $550{ }^{\circ} \mathrm{C}$ (the $B_{s} \sim 575^{\circ} \mathrm{C}$ ). At $625^{\circ} \mathrm{C}$, ferrite grains appear in the microstructure together with carbide colonies distributed in their interiors, Photo. 3(b).

\section{Mechanical Properties}

Figure 2 illustrates the variation in tensile strength (UTSS) as a function of temperature. It is seen that despite the large difference in the initial normalized and quenched strength values, closer values were at-

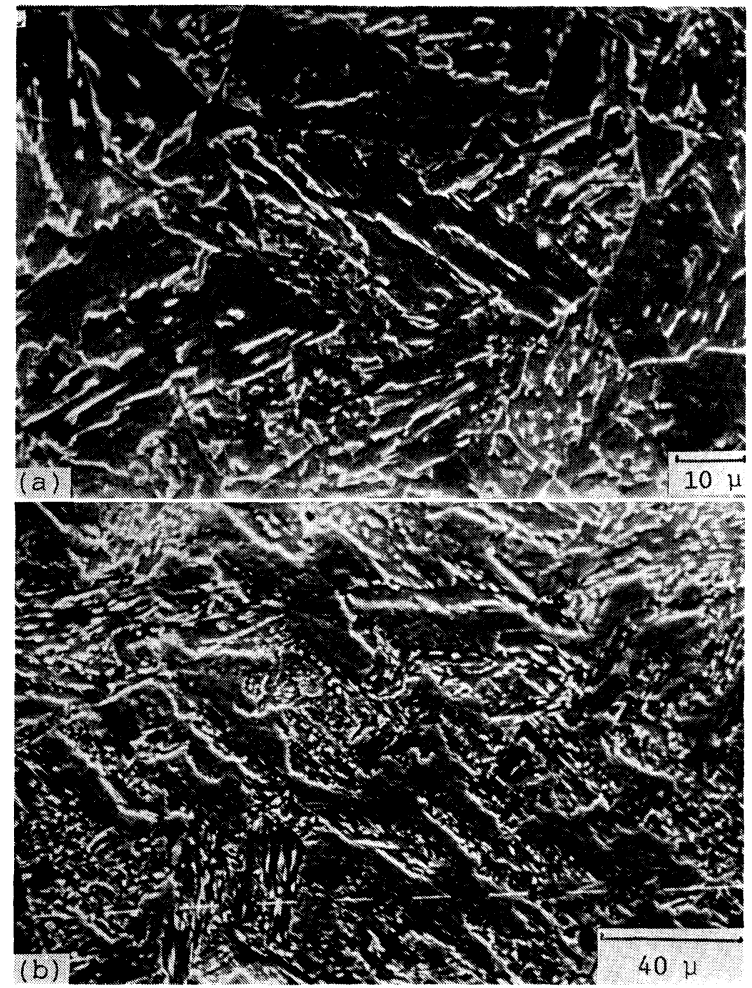

Photo. 2. Microstructure showing granular bainite in a) as-normalized, and b) normalized and tempered at $700^{\circ} \mathrm{C}$.

tained at $700{ }^{\circ} \mathrm{C}$. The isothermally transformed specimens were also found to approach the same strength levels of normalized and tempered steel at $625^{\circ} \mathrm{C}$. Examination of the microstructures reveals the formation of ferrite for the three steels in this range of temperatures. It is noted that bainite granules offer better resistance to softening than packet martensite or isothermal bainites (the fractional drop in UTS is about 0.15 for normalized steel at $700^{\circ} \mathrm{C}, 0.35$ for quenched steel at $700{ }^{\circ} \mathrm{C}$ and 0.35 for isothermal steel 
at $625^{\circ} \mathrm{C}$ ). These observations suggest that recovery of granular bainite may take place at early stages of tempering or during the normalizing process.

With regard to conventional quenched and tempered HSLA steels, in the present case the changes in ductility (as measured by total elongation (EL) or uniform elongation (UE)) were found mostly to decrease linearly with UTS (with varying slopes) as shown in Fig. 3(a). At a given strength, however, tempered martensite or tempered bainite has superior ductility as compared to conventional treatment. Figure $3(\mathrm{~b})$ reveals that the ratio of UE to EL is essentially constant for each process and falls in the range $0.6 \sim 0.7$ for all the three regimes studied. In similar

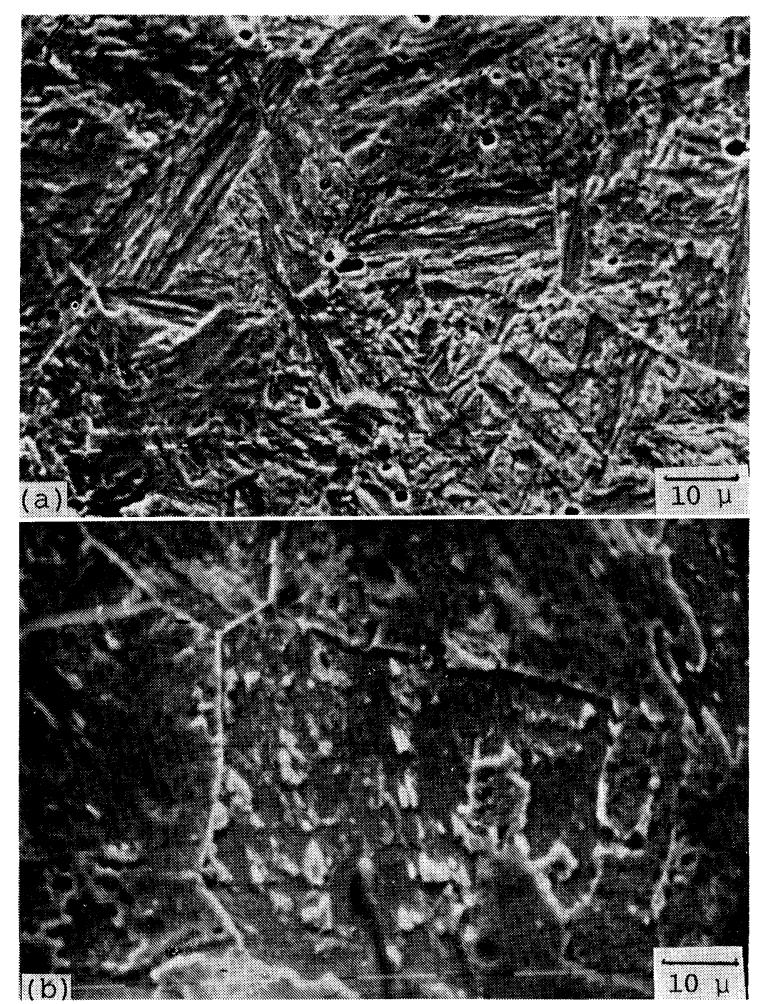

Photo. 3. Microstructure of the steel isothermally transformed at a) $350{ }^{\circ} \mathrm{C}$, showing mixed packets of martensite and bainite, and b) $625^{\circ} \mathrm{C}$, showing ferrite and carbide aggregates. steels, Marder ${ }^{15)}$ reported 0.75 for a dual-phase (ferrite and martensite) structure. Figure 4 exhibits a good correlation between the strain hardening exponent ' $n$ ' and true uniform elongation $\left(\mathrm{UE}_{t}\right)$, and the slope is unity for tempered bainite. The work of Davies $^{13)}$ on similar steels showed that the values of ' $n$ ' are 0.07 for packet martensite and 0.11 for bainite structure, which are in good agreement with the present data. In a previous study ${ }^{16)}$ on this steel, the slope for the $n-\mathrm{UE}_{t}$ relation was also unity on varying the volume fraction of second phase.

The effect of temperature on the product of tensile strength and total elongation (TS $\times \mathrm{EL}$ ) or uniform elongation (TS $\times \mathrm{UE}$ ) is demonstrated in Fig. 5. These two parameters are used to determine the strength-ductility relationship. Previous work on dual-phase steel $^{8)}$ reported at sharp drop-off in TS $\times$ EL parameter at a certain strength and that was attributed to premature void formation. Another research group ${ }^{15)}$ observed an identical trend for $\mathrm{TS} \times$ $\mathrm{UE}$, and found that both UE and EL are interchangeable.

The changes in toughness (as measured by unit propagation energy, UPE) with the temperature is shown in Fig. 6. All the three treatments studied reveal substantial improvement in toughness with no signs of temper embrittlement. It is inferred from Figs. 2, 3 and 6 that the toughness of a given steel is independent of the strength or ductility when the microstructure changes from martensite to lower bainite. However, a noticeable increase was achieved for upper bainite. Similar results have been obtained by Kunitake et al. ${ }^{7)}$ Kamada et al. ${ }^{6)}$ concluded that the strength of bainite depended on the transformation temperature more than on the alloying elements and the changes in the strength followed an opposite trend to the changes in toughness in $0.15 \% \mathrm{C}$ steel with $1.5 \% \mathrm{Cr}$ and Mo. The decrease in the toughness at $625^{\circ} \mathrm{C}$ transformation temperature, Fig. 6, is probably due to the appearance of proeutectoid ferrite. $^{1)}$ Comparison between Figs. 5 and 6 shows that the variations in $\mathrm{UPE}$ and $\mathrm{TS} \times \mathrm{EL}$ with temperature are almost following a similar trend.

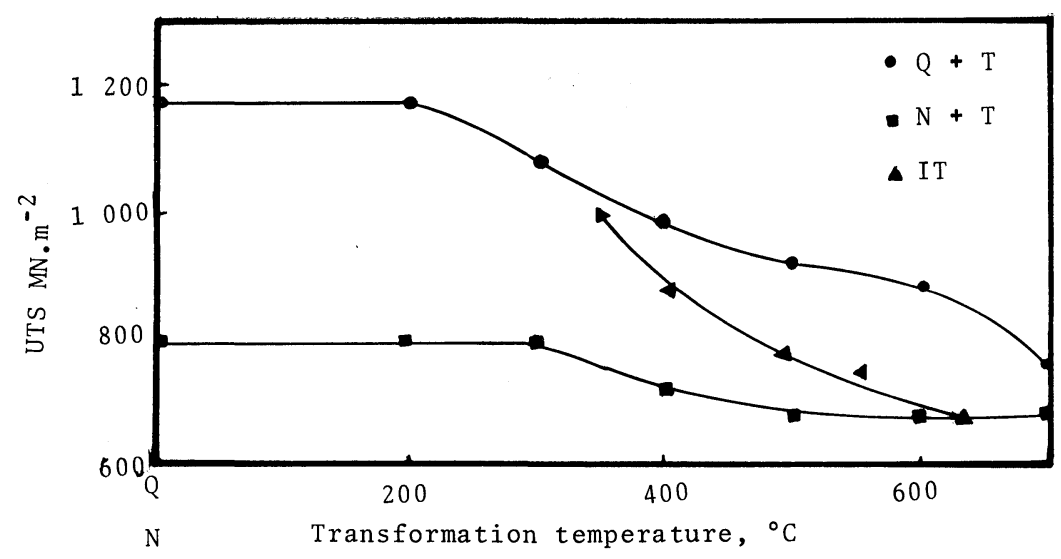

Fig. 2.

The variation in tensile strength as a function of temperature.*

\footnotetext{
* In this paper the abbreviations $Q+T, N+T$ and $I T$ will be used to describe quenched and tempered, normalized and tempered and isothermally transformed conditions, respectively. (see Figs. 3, 4 and 6)
} 
Fig. 3(a).

The variation in elongation as a function of tensile strength.

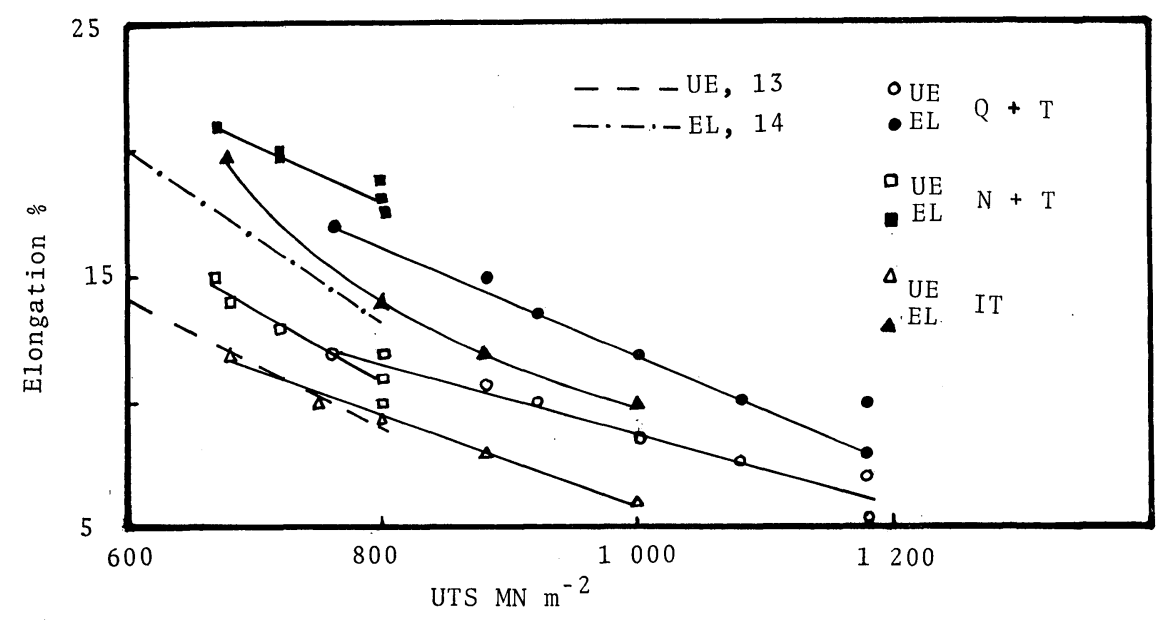

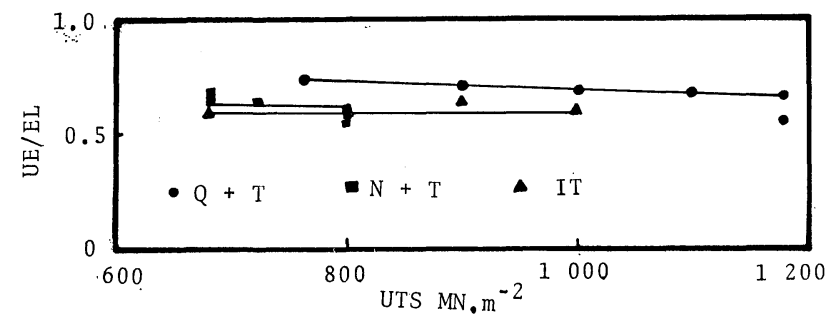

Fig. 3(b). The variation in UE/EL ratio as a function of tensile strength.

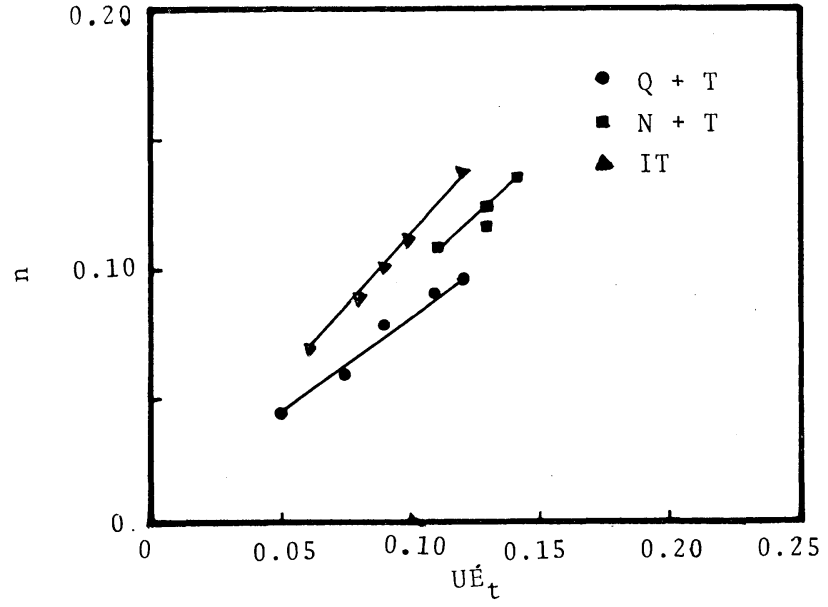

Fig. 4. The variation in strain hardening exponent ' $n$ ' as a function of true uniform elongation.

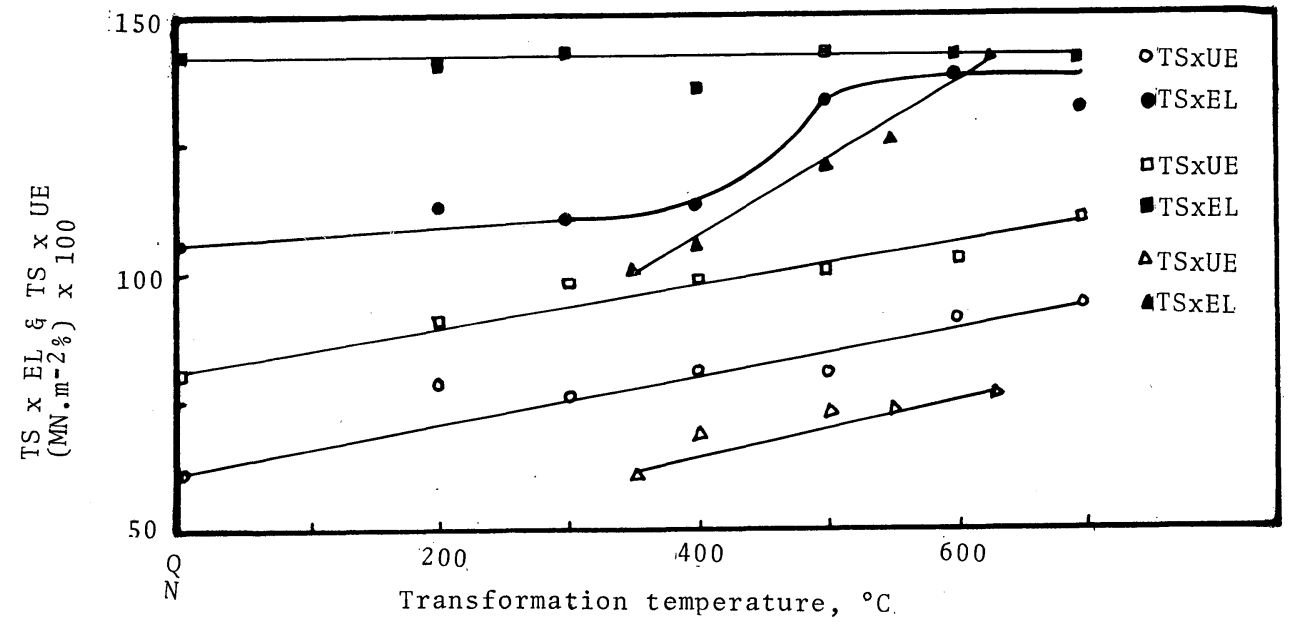

Fig. 5.

The variation in TS $\times E L$ and $\mathrm{TS} \times \mathrm{UE}$ as a function of temperature.
Fig. 6.

The variation in unit propagation energy as a function of temperature.

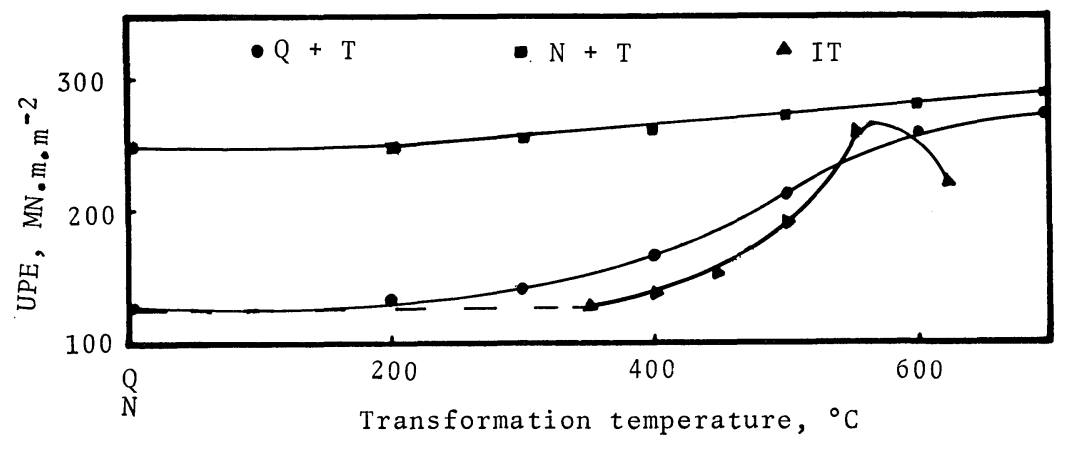




\section{Fracture Behaviour}

Investigations of the fracture behaviour of tear test specimens were focused on the areas representing crack initiation. The mode of fracture for martensite structure is mainly shear. Tempering leads to predomination of microvoids rupture at high temperatures, i.e., 600 and $700{ }^{\circ} \mathrm{C}$. An example is shown in Photo. 4. It is generally accepted that dimple fracture indicates a better toughness and the size of the dimple is directly related to the precipitated particles of second phase. ${ }^{17)}$ In Photo. 4, the dimples are in the order of $2 \sim 5 \mu \mathrm{m}$, whereas transmission electron microscopy reveals that the cementite particles precipitated at $700^{\circ} \mathrm{C}$ are in the range of $80 \sim 100 \AA$. Thus it is difficult to correlate the dimple size with the particle size. The normalized steel fractured through

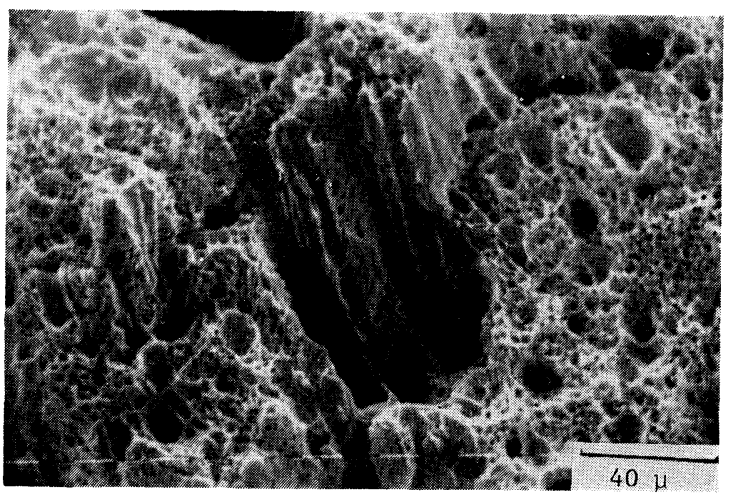

Photo. 4. Fractograph showing microvoid coalescence as predominant mode of rupture in quenched and tempered (at $600{ }^{\circ} \mathrm{C}$ ) steel.

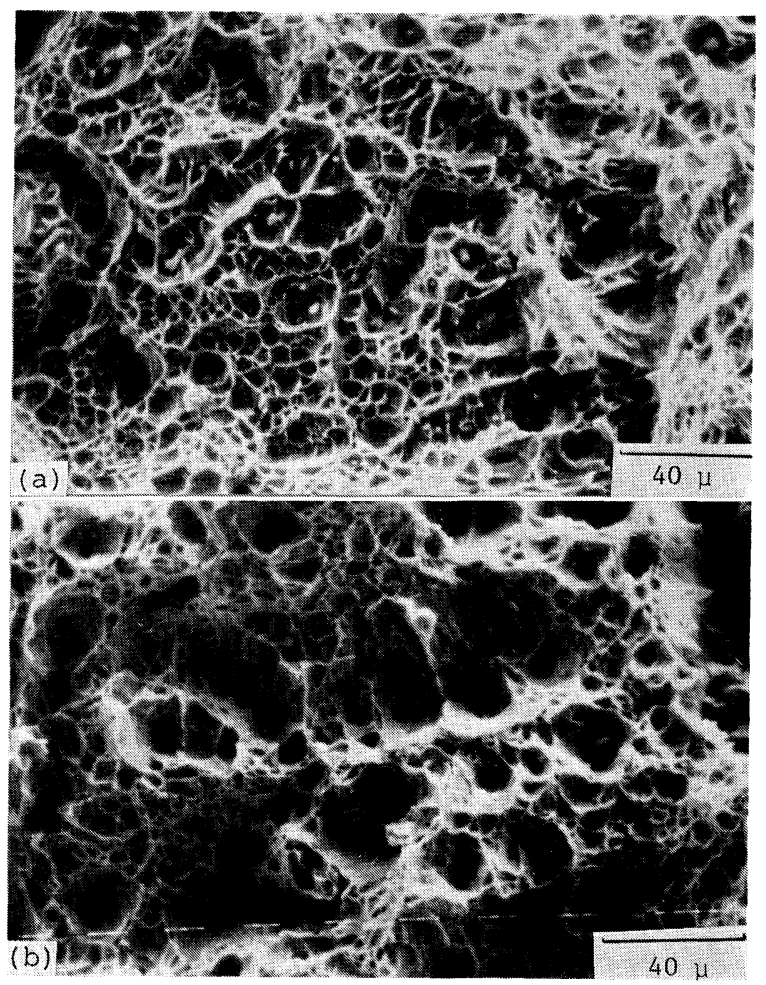

Photo. 5. Fractograph showing a) shallow dimples in normalized steel, and b) coarse dimples in normalized and tempered (at $700^{\circ} \mathrm{C}$ ) steel. formation of shallow dimples $(10 \sim 20 \mu \mathrm{m})$, Photo. $5(\mathrm{a})$. On tempering, the dimples appear much deeper (Photo. 5(b)) than in the case of tempered martensite (Photo. 4), though both achieved equivalent toughness levels. The present results suggest that the
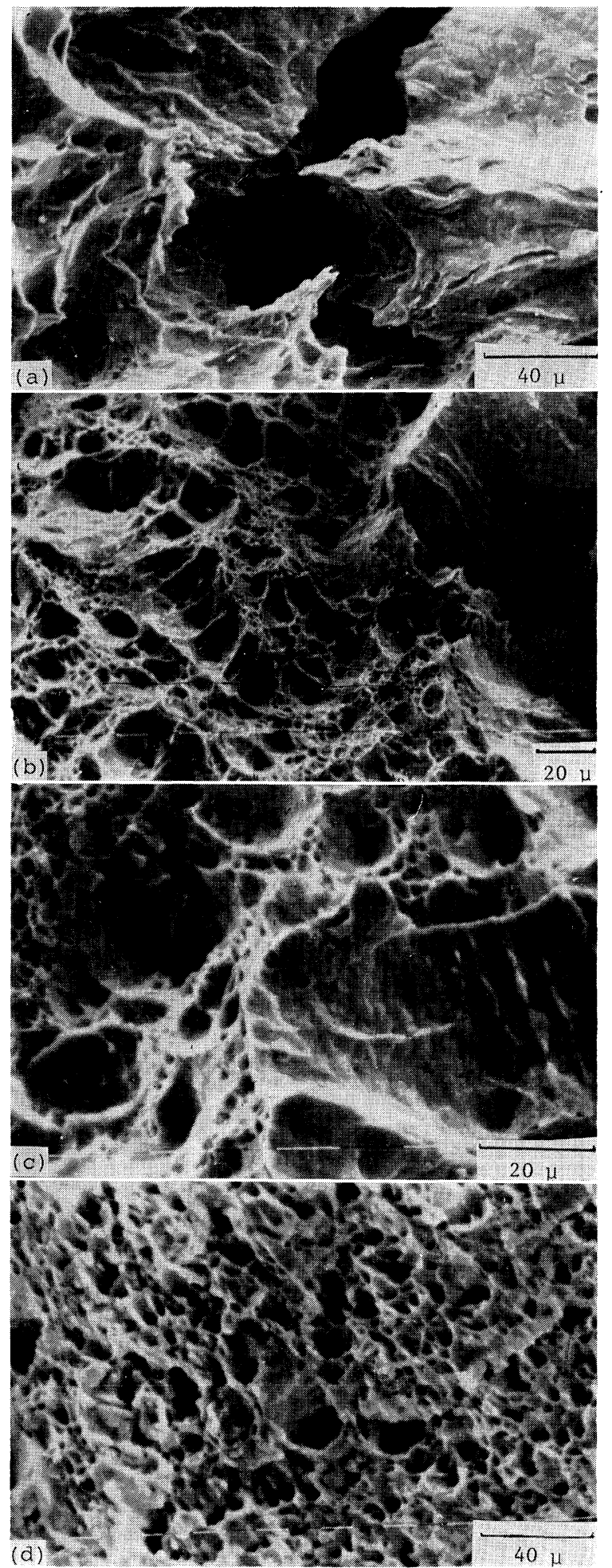

(a) $350^{\circ} \mathrm{C}$ showing secondary crack with quasicleavage facets

(b) $400^{\circ} \mathrm{C}$ showing mixed shear and dimple rupture

(c) $550^{\circ} \mathrm{C}$ showing dimple rupture

(d) $625{ }^{\circ} \mathrm{C}$ showing dimple rupture

Photo. 6. Fractograph of isothermally transformed steel. 
steel plasticity may have a significant role on the dimple size. Since the granules or islands in normalized structure constitute a large number of bainite laths, $\left.{ }^{9}\right)$ they are more easily deformed and are not, therefore, expected to crack. Thus the voids are likely to nucleate at the massive ferrite/bainite granule interfaces. This mechanism, however, is common in fine fibrous and fine globular dual-phase structure. ${ }^{18)}$

In Photo. 6(a) is exhibited the fracture surface of steel isothermally transformed at $350^{\circ} \mathrm{C}$. As seen, several transcrystalline cracks appear. It is worth recalling that toughness (see Fig. 6) associates with an increase in proportion of voids as is evident from Photo. 6(b) for lower bainite and in Photo. 6(c) for granular bainite at $550^{\circ} \mathrm{C}$. Transformation at 625 ${ }^{\circ} \mathrm{G}$ reveals coarse microvoids, Photo. 6(d), and the voids are so deep that their bottoms can not be photographed even at high magnifications. Thus it seems reasonable to assume that beyond a certain size of the voids, the toughness is decreased.

\section{Summary and Conclusions}

(1) Martensite is the product of quenching, whereas normalizing process is sufficient to induce bainite reaction. Both the martensite packets and bainite granules are retained on tempering at elevated temperatures, i.e., 600 and $700{ }^{\circ} \mathrm{G}$. Isothermal transformation results in mixed martensite and bainites at $350{ }^{\circ} \mathrm{C}$, lower bainite at $400^{\circ} \mathrm{C}$, upper bainite at 450 ${ }^{\circ} \mathrm{C}$, granular bainite at $550{ }^{\circ} \mathrm{C}$ and polygonal ferrite at $625^{\circ} \mathrm{C}$.

(2) The normalized structure offers higher resistance to softening on tempering than martensite or isothermal bainites. Both total elongation and uniform elongation seem to vary linearly with strength. The uniform elongation to total elongation ratios are in the range $0.6 \sim 0.7$. Although the strain hardening exponent changes linearly with the true uniform elongation for martensite and isothermal bainites, the slope is unity only for normalized steel. There is a marked difference in using $\mathrm{TS} \times \mathrm{EL}$ or $\mathrm{TS} \times \mathrm{UE}$ in determining the strength-ductility relation. The toughness seems to change in a similar trend to the $\mathrm{TS} \times \mathrm{EL}$ parameter as a function of temperature.
(3) The fracture mode of martensite is chiefly shear which changes into microvoids coalescence rupture on tempering at high temperatures. The void nucleation and coalescence are the main fracture mechanism for granular bainite. Lower bainite fractures by shear whereas dimples and shear operate together for upper bainite and complete dimple rupture is observed for ferrite-carbide structure.

\section{Acknowledgements}

The author wishes to express his sincere thanks to Professor A. A. Abdul Azim and Dr. A. A. Ramadan, Central Metallurgical Research and Development Institute, for their helpful discussion and comments on the manuscript.

\section{REFERENGES}

1) P. L. Manganon: Metall. Trans., 7 (1976), 1389.

2) K. J. Irvine and F. B. Pickering: JISI, 201 (1963), 518.

3) K. J. Irvine, F. B. Pickering, W. G. Heselwood and M. Atkins: JISI, 186 (1957), 54.

4) V. F. Zackay and W. M. Justusson: Iron Steel Inst. Spec. Rep., (1962), No. 126, 14.

5) W. W. Gerberich et al.: ASTM Spec. Tech. Publ., 370 (1965), 154.

6) A. Kamada, N. Koshizuka and T. Funakoshi: Trans. ISIJ, 18 (1978), 16.

7) T. Kunitake, F. Terasaki, Y. Ohmori and H. Ohtani: Sumitomo Research, 8 (1972), 647.

8) K. Araki, Y. Takada and N. Nakaoku: Trans. ISIJ, 17 (1977), 710.

9) F. H. Samuel and D. S. Sarma: Met. Sci., 14 (1980), 101.

10) F. H. Samuel: Ph.D. Thesis, Banaras Hindu University, (1979).

11) S. K. Sharma, F. H. Samuel and D. S. Sarma: Steel India, 1 (1979), 7.

12) K. Onel and J. Nutting: Met. Sci., 15 (1981), 89.

13) R. G. Davies: Met. Trans., 9 (1978), 671.

14) J. Morrow and G. Tither: J. Metals, 30 (1978), 16.

15) A. R. Marder: Met. Trans., 13 (1982), 85.

16) F. H. Samuel and A. A. Hussein: 2nd Conf. on Mechanical Design and Production, Cairo University, Cairo, December, 1982.

17) Metals Handbook, 8th ed., IX, ASM, Ohio, (1974).

18) N. J. Kim and G. Thomas: Met. Trans., 12 (1981), 483. 